\title{
Scleroderma and malignancy: an epidemiological study
}

\author{
Ann K Rosenthal, Joseph K McLaughlin, Martha S Linet, Ingemar Persson
}

\begin{abstract}
Objectives-Although case reports and some patient series suggest an increased risk of cancer among patients with scleroderma, there are no population based studies to support this association. A population based follow up study was therefore carried out of 233 patients with scleroderma from the six-county Uppsala health care region of Sweden for the time period 1955-84.
\end{abstract}

Methods-Using the inpatient registry for the Uppsala health care region, all patients with scleroderma were identified. Their unique identification codes were then used to perform a record linkage with the National Cancer Registry. Expected cancer rates were determined using the age and gender specific rates for the Uppsala health care region.

Results-The standardised incidence ratio (SIR) for all cancers among these patients was significantly increased (SIR=2.4; 95\% CI=1.5 to 3.6). The SIRs for lung cancer $(\mathrm{SIR}=7 \cdot 8 ; 95 \% \mathrm{CI}=2 \cdot 5$ to $18 \cdot 2)$ and non-Hodgkin's lymphoma (SIR=9.6; $95 \% \mathrm{CI}=1 \cdot 1$ to $34 \cdot 5$ ) were also significantly increased. Excluding patients who were diagnosed with cancer within a year of their scleroderma diagnosis resulted in similar findings, though the SIR for nonHodgkin's lymphoma was no longer statistically significant.

Conclusions-Larger population based investigations of cancer risk among patients with scleroderma are needed to confirm these initial findings and to evaluate in greater detail possible cancer risk among these patients.

(Ann Rheum Dis 1993; 52: 531-533)

Scleroderma is a diffuse connective tissue disease causing fibrosis of the skin, lungs, gastrointestinal tract, and other visceral organs. ${ }^{1}$ The association between scleroderma and malignancy has been an area of debate. ${ }^{23}$ Several studies of patients with scleroderma at large referral centres showed prevalences of malignancy between $2 \cdot 6$ and $5 \%$, including increased numbers of lung, breast, haematopoietic, and lymphoproliferative malignancies. ${ }^{4-6}$ Case reports have described ovarian and oesophageal cancers among patients with scleroderma. ${ }^{7}$ To our knowledge, a population based follow up study on the incidence of malignancy among patients with scleroderma has not been published.
We report herein the results of a population based study examining scleroderma and subsequent malignancy.

\section{Subjects and methods}

COHORT

The six county Uppsala health care region in central Sweden includes a population of 1.2-1.3 million. As almost no private inpatient treatment exists in Sweden, all hospital based care is recorded in the inpatient discharge registry, and in effect is population based. For the present analysis we used data from this registry for the years $1965-83$, which included information on any operations performed, and up to eight discharge diagnoses. Diagnoses are coded according to the seventh revision of International Classification of Diseases (ICD) code up to 1968 and the eighth revision thereafter. Underreporting for the inpatient discharge registry is estimated at $<2 \%$. ${ }^{8}$

All computer records containing ICD codes for scleroderma were reviewed. For the ICD 7 th revision, the codes used for scleroderma were 710.05 (28 patients) and 710.06 (eight patients); for the ICD 8th revision codes 734.00 (74 patients), 734.01 (36 patients), and 734.09 (87 patients) were included. Localised scleroderma and all overlap syndromes were excluded. Patients with incomplete registration numbers or invalid codes were also excluded (nine patients). The inpatient discharge registry has been used to examine a number of disease and subsequent cancer relations. ${ }^{9} 10$

FOLLOW UP

After identifying all eligible patients, each patient's unique 10 digit national registration number was used to perform a record linkage with the National Cancer Registry (to determine cancer incidence) and with the National Causes of Death Registry (to determine date of death). By law, all cancers must be reported to the National Cancer Registry, which has almost complete ascertainment. ${ }^{11}$ The time of observation was recorded as the registration date at the hospital for the first diagnosis of scleroderma to the time of cancer diagnosis, death, or the end of the observation period (31 December 1984).

\section{STATISTICAL METHODS}

We calculated the expected number of cancers by multiplying the number of patient years by the age and sex specific cancer rates for the Uppsala health care region provided by the National Cancer Registry. The distribution is
Mex 118, Milwauk

$8700 \mathrm{~W}$ Wisconsin Avenue,

Milwaukee,

WI 53226, USA

Accepted for publication

16 March 1993 
Table 1 Characteristics of patients with scleroderma in the Uppsala health care region (1965-83)

\begin{tabular}{lr}
\hline No of patients with scleroderma & 233 \\
Women & 144 \\
Men & 89 \\
Number of subsequent cancers & 22 \\
Total person years & 1195 \\
Average years of follow-up & $5 \cdot 1$ \\
Average age at entry (years) & $57 \cdot 9$ \\
Average age at cancer diagnosis (years) & $69 \cdot 4$ \\
Average calendar year of cancer diagnosis & 1977 \\
\hline
\end{tabular}

assumed to follow a Poisson distribution. For each cancer type the standardised incidence ratio (SIR), the observed/expected ratio, and the $95 \%$ confidence interval were determined. ${ }^{12}$ Owing to the limited size of the scleroderma cohort, men and women were combined for analysis.

\section{Results}

We identified 233 people diagnosed with scleroderma ( 144 women, 89 men) during the study period. A total of 1195 patient years were accrued. The mean age at entry was 57.9 years and the average length of follow up was $5 \cdot 1$ years (table 1 ).

Cancer rates for patients with scleroderma were compared with those of the general Uppsala population for the time period of the study (table 2). The overall cancer SIR for the scleroderma cohort was $2 \cdot 4$ (95\% confidence interval (CI) 1.5 to 3.6 ), indicating a significantly increased rate of malignancy among patients with this disease. The overall cancer risk was increased in both men $(\mathrm{SIR}=1 \cdot 8)$ and women (SIR=2.9), though only among women was the increased risk statistically significant.

For individual cancer sites there were statistically significant excesses of cancer of the lung (SIR=7.8;95\% CI 2.5 to 18.2 ) and haematopoietic cancers due to an increased risk of non-Hodgkin's lymphoma (SIR=9.6; 95\% CI $1 \cdot 1$ to 34.5 ) (table 2). Of the five lung cancers, one was an adenocarcinoma, three were squamous cell cancers, and one was an unspecified epithelial cancer.

To correct for possible selection bias, the data were analysed excluding the first year after diagnosis. Significant increases still remained for overall cancer occurrence and for lung cancer (table 3 ). The excess of non-Hodgkin's lymphoma also remained, though it was no longer statistically significant as it was based on only one case. To evaluate bias further we restricted the cohort to patients whose primary discharge diagnosis was scleroderma and found no difference in risk estimates for cancers overall, lung cancer, or non-Hodgkin's lymphoma.

Table 2 Standardised incidence ratios (SIR) of selected cancers among patients with scleroderma from the Uppsala health care region (1965-84)

\begin{tabular}{lcccl}
\hline Cancer sites & Observed & Expected & SIR & $\begin{array}{l}\text { 95\% Confidence } \\
\text { interval }\end{array}$ \\
\hline All cancers & 22 & $9 \cdot 27$ & $2 \cdot 4$ & $1 \cdot 5$ to $3 \cdot 6$ \\
Lung cancer & 5 & $0 \cdot 64$ & $7 \cdot 8$ & $2 \cdot 5$ to $18 \cdot 2$ \\
Breast cancer & 2 & $1 \cdot 19$ & $1 \cdot 7$ & $0 \cdot 2$ to $6 \cdot 1$ \\
Ovarian cancer & 1 & $0 \cdot 28$ & 3.6 & $0 \cdot 1$ to $19 \cdot 9$ \\
Oesophageal cancer & 0 & $0 \cdot 09$ & - & - \\
Lymphatic and haematopoietic cancers & 3 & $0 \cdot 64$ & $4 \cdot 7$ & $0 \cdot 9$ to $13 \cdot 7$ \\
$\quad$ Non-Hodgkin's lymphoma & 2 & $0 \cdot 20$ & 9.6 & $1 \cdot 1$ to $34 \cdot 5$ \\
\hline
\end{tabular}

Patients with scleroderma in this cohort did not have a significantly increased risk of breast, ovarian, or oesophageal cancers, though the power to detect excess risk for these tumours was limited.

\section{Discussion}

Several early studies concluded that there was no increase in malignancy among patients with scleroderma, but most of these were reports on the prevalence of cancer at initial presentation in tertiary referral centres ${ }^{4}{ }^{13}$ or the prevalence of malignancies at necropsy among patients with scleroderma. ${ }^{14-16}$ The risk of cancer cannot be assessed in these studies because no appropriate comparison data were available to calculate rates. In one study in which risk was calculated, Black et $a l^{17}$ found no increased incidence of cancer among 27 patients with scleroderma from a single centre in Australia.

In contrast, Roumm and Medsger ${ }^{5}$ reported an increased risk for cancer of 1.8 among 262 patients with scleroderma from a tertiary care hospital in Pittsburgh compared with expected rates. This increase was largely accounted for by an increase in lung cancer (relative risk $4 \cdot 4$ ). Another follow up study, ${ }^{18}$ as well as prevalence ${ }^{13}$ and necropsy data, ${ }^{16}$ have suggested that the risk of lung cancer may be increased among patients with scleroderma. Our data support this association. Although alveolar cell carcinoma has been linked with scleroderma in clinical reports, ${ }^{19} 20$ squamous cell cancers predominated in our patients. Pulmonary fibrosis associated with scleroderma may increase the risk of lung cancer. Growth factors implicated in fibrosis may be mitogenic and cause excess cellular division resulting in transformation. ${ }^{21}$ Alternatively, changes in the extracellular matrix, which plays an important part in growth and differentiation, may affect the behaviour of normal cells. ${ }^{22}$

We observed a suggestive excess risk of nonHodgkin's lymphoma among patients with scleroderma. No increase of non-Hodgkin's lymphoma was found in two earlier follow up studies of patients, ${ }^{5} 17$ nor has an excess of scleroderma been reported in case-control studies of non-Hodgkin's lymphoma. ${ }^{23-26}$ Patients with other connective tissue disorders, however, notably rheumatoid arthritis and Sjögren's syndrome, have shown an excess risk of non-Hodgkin's lymphoma. ${ }^{27-29}$ Moreover, cases of non-Hodgkin's lymphoma were described in a large series of patients with scleroderma referred to the Mayo Clinic, ${ }^{4} 30$ and in a recent case report from France. ${ }^{31}$ It is possible that the increased risk of nonHodgkin's lymphoma among patients with scleroderma is due to the use of cytotoxic drugs. ${ }^{2}$

Although patients with scleroderma have been reported with oesophageal cancer, ${ }^{32}$ particularly among those with Barrett's syndrome, ${ }^{33}$ we observed none. Breast and ovarian cancers have been described in case reports ${ }^{74}$ and in a large series ${ }^{4}$ of patients with scleroderma. We did not observe any excess of breast 
Table 3 Standardised incidence ratios (SIR) of selected cancers among patients with scleroderma from the Uppsala health care region (1965-84) excluding those occurring in the first year of follow up

\begin{tabular}{lcccl}
\hline Cancer sites & Observed & Expected & SIR & $\begin{array}{l}\text { 95\% Confidence } \\
\text { interval }\end{array}$ \\
\hline All cancers & 16 & $7 \cdot 89$ & $2 \cdot 0$ & $1 \cdot 2$ to 3.3 \\
Lung cancer & 4 & $0 \cdot 54$ & $7 \cdot 4$ & $2 \cdot 0$ to 18.8 \\
Breast cancer & 1 & $1 \cdot 01$ & 1.0 & 0.0 to 5.5 \\
Ovarian cancer & 0 & $0 \cdot 24$ & - & - \\
Oesophageal cancer & 0 & $0 \cdot 07$ & - & - \\
Lymphatic and haematopoietic cancers & 2 & $0 \cdot 55$ & 3.7 & $0 \cdot 4$ to 13.3 \\
Non-Hodgkin's lymphoma & 1 & $0 \cdot 18$ & 5.6 & $0 \cdot 1$ to 31.1 \\
\hline
\end{tabular}

or ovarian cancers after the exclusion of the first year of follow up, but our statistical power to evaluate these associations was limited.

We evaluated selection bias in two ways in this study. First, we excluded all cancers occurring up to one year after the diagnosis of scleroderma to avoid those patients whose underlying cancer was a possible cause of admission to hospital. Second, we restricted the cohort to only those patients with scleroderma as their primary discharge diagnosis to assess Berkson's bias. Neither of these manoeuvres materially changed the results.

The advantages of this study include its population based nature and the near complete coverage of the cancer registry and the patient discharge registry, which includes patients admitted to hospital anywhere in Sweden with scleroderma who lived in the Uppsala region during the study period. On the other hand, the patient cohort was relatively small and included only those patients with a hospital diagnosis. These patients may be older and have more severe scleroderma than patients not admitted to hospital. The average age at entry to the cohort, 57.9 years, suggests that the patients are older than the 45-54 year old age group which is the most common age group at time of diagnosis. ${ }^{3}$ The ratio of women to men in our cohort, $1 \cdot 6: 1$, is lower than previously reported, but more in line with the sex ratios found among older patients. ${ }^{3}$ Despite these problems, we believe that this study may provide useful epidemiological clues.

In summary, we have observed an increased risk of lung cancer and a suggestive excess of non-Hodgkin's lymphoma in a cohort of patients with scleroderma. Larger studies are needed to confirm these findings and to evaluate other site specific cancers thought to be in excess among these patients.

Dr Rosenthal is a recipient of a postdoctoral fellowship from the Arthritis Foundation. We thank Mr Eric Berger of IMS, Inc. for computer support.

1 Medsger T A. Systemic sclerosis (scleroderma), localized scleroderma, eosinophilic fasciitis, and calcinosis. In: McCarty D J, ed. Arthritis and allied conditions. Philadelphia: Lea and Febiger, 1989; 1118-65.

2 Medsger T A. Systemic sclerosis and malignancy-are they related? [editorial]. $\mathcal{J}$ Rheumatol 1985; 12: 1041-3.

3 Silman A J. Epidemiology of scleroderma. Ann Rheum Dis 1991; 50 (suppl 4): 846-53.

$1991 ; 50$ (suppl 4): 846-53.
4 Duncan S C, Winkelman R K. Cancer and scleroderma. Arch Dermatol 1979; 115: 950-5.

5 Roumm A D, Medsger T A. Cancer and systemic sclerosis: an epidemiologic study. Arthritis Rheum 1985; 28
6 Tuffanelli D L, Winkelman R K. Systemic scleroderma: a clinical study of 727 cases. Arch Dermatol 1961; 84: 359-71

7 Talbott J H, Barrocas M. Progressive systemic sclerosis (PSS) and malignancy, pulmonary and non-pulmonary. Medicine (Baltimore) 1979; 58: 182-207.

8 Naesson T, Parker R, Persson I, Zack M, Adami H O. Time trend in rates of first hip fracture in the Uppsala health care region. Sweden 1965-1983. Am F Epidemiol 1989; 130: 289-99.

9 Pinczowski D, McLaughlin J K, Lackgren G, Adami H-O, Persson I. Occurrence of testicular cancer in patients operated on for cryptorchidism and inguinal hernia. $\mathcal{F}$ Urol 1991;146: 1291-4.

10 Adami $\mathrm{H}-\mathrm{O}$, McLaughlin J K, Ekbom A, Berne C, Silverman D, Hacker D, Persson I. Cancer risk in patients with diabetes mellitus. Cancer Causes and Control 1991; 2: with diabet

11 Mattson B. The completeness of registration in the Swedish cancer registry. Stockholm: Swedish Board of Health and Welfare; 1977. Stat Rep HS 1977 Report No.: 15.

12 Bailar J C, Ederer F. Significance factors for the ratio of a Poisson variable to its expectations. Biometrics 1964; 20: 639-43.

13 Winkelman R K, Flach D B, Unni K K. Lung cancer and scleroderma. Arch Dermatol Res 1988; 280 (suppl): S15-8.

14 D'Angelo W A, Fries J F, Masi A T, Shulman L E. Pathologic observation in systemic sclerosis (scleroderma). Am f Med 1969; 46: 428-40.

15 Piper W N, Helwig E B. Progressive systemic sclerosis. Arch Dermatol 1955; 72: 535-46.

16 Okayasu I, Mizutani H, Kurihara H, Yanagisawa F. Cance in collagen disease: a statistical analysis by reviewing the annual of pathologic autopsy cases in Japan. Cancer 1984 54: $1841-4$

17 Black K A, Zilko P J, Dawkins R L, Armstrong B K, Mastaglia G L. Cancer in connective tissue disease. Arthritis Rheum 1982; 25: 1130-3.

18 Peters-Golden M, Wise R A, Hochberg M, Stevens M B, Wigley $F$ M. Incidence of lung cancer in systemic sclerosis. F Rheumatol 1985; 12: 1136-9.

19 Zatuchni J, Campbell W N, Zarafonetis C J D. Pulmonary fibrosis and terminal bronchiolar ("alveolar cell") carcinoma in scleroderma. Cancer 1953; 6: 1147-58.

20 Talbott J H, Barrocas M. Carcinoma of the lung in progressive systemic sclerosis: a tabular review of the literature and a detailed report of the roentgenographic changes in two cases. Semin Arthritis Rheum 1980; 9. 1078-86.

21 LeRoy E C, Smith E A, Kahaleh M B, Trojanowska M, Silver R M. A strategy for determining the pathogenesis of systemic sclerosis: is transforming growth factor $\beta$ the of systemic sclerosis: is transforming grow
answer? Arthritis Rheum 1989; 32: 817-24.

22 Allen-Hoffman B L, Crankshaw C L, Mosher D F. Transforming growth factor $\beta$ increases cell surface binding and assembly of exogenous (plasma) fibronectin by normal human fibroblasts. Mol Cell Biol 1988; 8 4234-42.

23 Tielsch J M, Linet M S, Szklo M. Acquired disorders affecting the immune system and non-Hodgkin's lymphoma. Prev Med 1987; 16: 96-106.

24 Cartwright R A, McKinney P A, O'Brien C, et al. NonHodgkin's lymphoma: case-control epidemiological study in Yorkshire. Leuk Res 1988; 12: 81-8.

25 Franceschi S, Serraino D, Bidoli E, Talamini R, Tirelli V, Carbone A, LaVecchia C. The epidemiology of nonHodgkin's lymphoma in the north-east of Italy: a hospitalbased case-control study. Leuk Res 1989; 13: 465-72.

26 Greene $M$ H. Non-Hodgkin's lymphoma and mycosis fungoides. In: Schottenfeld D, Fraumeni J F F Jr, eds. Cancer epidemiology and prevention. Philadelphia Saunders, 1982: 754-78.

27 Hakulinen T, Isomaki H, Knekt P. Rheumatoid arthritis and cancer studies based on linking nationwide registries in Finland. Am f Med 1985; 78: (suppl 1A): 29-32.

28 Pearce N, Porter M. Association of non-Hodgkin's lymphoma with rheumatoid arthritis. Am $\mathcal{F}$ Med 1986; 81: $747-8$.

29 Kassan S S, Thomas T L, Moutsopoulos H M, et al. Increased risk of lymphoma in sicca syndrome. Ann Intern Med 1978; 89: 888-92.

30 Doyle J A, Connolly S M, Haogland H C. Hematologic disease in scleroderma syndromes. Acta Dermatol Venereo 1985; 65: 521-5.

31 Pulik M, Teillet-Thiebaud F, Mahe A, Teillet F. Association lymphome nonhodgkinien et sclerodermie. Presse Med 1991; 20: 1513-4.

32 Segel M C, Campbell W L, Medsger T A Jr, et al. Systemic sclerosis (scleroderma) and esophageal adenocarcinoma: is increased patient screening necessary? Gastroenterology 1985; 89: 485-8.

33 Katzka D A, Reynolds J C, Saul S H, et al. Barrett's metaplasia and adenocarcinoma of the esophagus in scleroderma. Am $¥$ Med $1987 ; 82 ; 46-52$.

34 Lee P, Alderdice C, Wilkinson S, Keystone E C, Urowitz M B, Gladman D D. Malignancy in progressive Urowitz M B, Gladman D D. Malignancy in progressive [letter]. F Rheumatol 1983; 10: 665-6. 